\title{
Gastric variceal bleeding due to pancreatitis-induced splenic vein thrombosis
}

\author{
Antonio Gotto, ${ }^{1}$ Michael Lieberman, ${ }^{1}$ Mark Pochapin ${ }^{2}$
}

${ }^{1}$ Weill Cornell Medical College, New York, New York, USA

${ }^{2}$ New York University,

New York, New York, USA

Correspondence to

Dr Antonio Gotto,

amg2004@med.cornell.edu

Accepted 5 March 2014

\section{SUMMARY}

Obscure gastrointestinal bleeding is a common clinical scenario. In the upper gastrointestinal tract, gastric varices can be frequently overlooked on endoscopy, particularly if not suspected or volume depleted. We report a case of suspected gastrointestinal bleeding in a patient with a childhood history of pancreatitis, who also experienced severe epigastric pain while in hospital. After transfer to an academic medical centre, the presence of gastric varices was identified and presumed to be due to splenic vein thrombosis. Pancreatitis is the most common cause of splenic vein thrombosis and accords with the patient's history, even though it occurred many years previously. This case highlights the importance of recognising pancreatitis-induced splenic vein thrombosis as a possible aetiology for upper gastrointestinal bleeding.

\section{BACKGROUND}

Suspected upper gastrointestinal (GI) bleeding is a common clinical scenario, although often it can be difficult to identify the source. ${ }^{1}$ In the upper GI tract, commonly overlooked lesions include peptic ulcers, fundic varices, angioectasias and Dieulafoy's lesion. Gastric variceal bleeding due to splenic vein thrombosis (SVT) is an infrequent complication of pancreatitis that can be managed with splenectomy. In this article, we report a case of obscure GI bleeding in which a diagnosis of SVT was deduced only after gastric varices were identified on repeat endoscopy.

Pancreatitis-induced SVT was first described in the medical literature in $1920 .^{2}$ Chronic pancreatitis and pancreatic inflammatory disease are the most common causes of SVT, accounting for more than half of all reported cases, although most patients with SVT are asymptomatic. ${ }^{3}$ A sizeable proportion of patients with isolated SVT, between $17 \%$ and $55 \%$, are estimated to develop gastric or oesophageal varices. ${ }^{4}{ }^{5}$ Bleeding from varices of this aetiology occurs infrequently, in around 4$17 \%$ of patients. ${ }^{3}{ }^{5-7}$ Variceal haemorrhage presenting as anaemia, melena or haematemesis may be the first clinical sign of SVT. In approximately one-quarter of patients, abdominal pain from a variety of other causes, including chronic pancreatitis, pseudocyst, carcinoma or splenomegaly, is the presenting symptom. ${ }^{4}$

\section{CASE PRESENTATION}

A 25 -year-old woman, an assistant chef in a worldclass restaurant, presented to her local emergency room after visiting her primary care physician with complaints of weakness, dizziness and headache. She had experienced an episode of melena 2 days previously and had a positive faecal occult blood test. In the emergency room, her haemoglobin fell to $6.8 \mathrm{~g} / \mathrm{dL}$, she had low liver enzymes, her pulse was approximately $110 \mathrm{bpm}$, and her blood pressure was 106/88 mm Hg. After blood transfusions, her haemoglobin stabilised at $9.8 \mathrm{~g} / \mathrm{dL}$. She reported, at the age of 11 years, having had a pancreatic resection for pancreatitis (Roux-en-Y pancreaticojejunostomy), thought to be caused by a blunt abdominal trauma. She took non-steroidal anti-inflammatory drugs (NSAIDs) a couple of times per month and drank heavily only on weekends. An upper endoscopy was performed and showed no old or fresh blood in the stomach or duodenum. Multiple gastric polyps were seen in the gastric body and fundus, but the stomach and oesophagus looked otherwise normal. A radionuclide GI bleeding scan was positive for bleeding in the left upper quadrant and suspicious for bleeding within the proximal small bowel.

On her second day in hospital, the patient began complaining of severe pain in the right upper quadrant. A CT scan of the abdomen and pelvis showed no evidence of obstruction or GI perforation, but minimal pericholecystic fluid, moderate pelvic fluid and congestive features of bilateral pleural effusions were observed. Infiltration of mesenteric fat in the upper abdomen was thought to be secondary to postoperative changes from the Roux-en-Y procedure. On the third day, a push enteroscopy was performed to evaluate bleeding in the small bowel. The enteroscope was advanced to the Roux-en-Y anastomosis, which appeared normal. There was possibly a clot at the opening of the blind loop that washed off easily, but no bleeding was seen elsewhere. An ultrasound of the right upper quadrant was performed to evaluate the epigastric pain. Small ascites and right pleural effusions were seen, but the ultrasound was otherwise normal.

After the fourth day, the patient was transferred to an academic teaching hospital. A colonoscopy was performed and appeared normal, with no evidence of blood. A repeated upper GI endoscopy identified moderate-sized gastric varices in the fundus (figure 1A, circled, and figure 1B, arrows), with mild erythema but no stigmata of recent bleeding. Two gastric polyps were seen overlying two varices, but the rest of the stomach, the oesophagus and the duodenum appeared normal. The CT scan of the abdomen and pelvis from the local hospital was submitted for review. Perigastric and perisplenic veins were found to be moderately dilated and suggestive of varices, and the liver appeared mildly enlarged. The overall impression was of a fluid overloaded state, likely the cause of the patient's ascites and pleural effusions. 

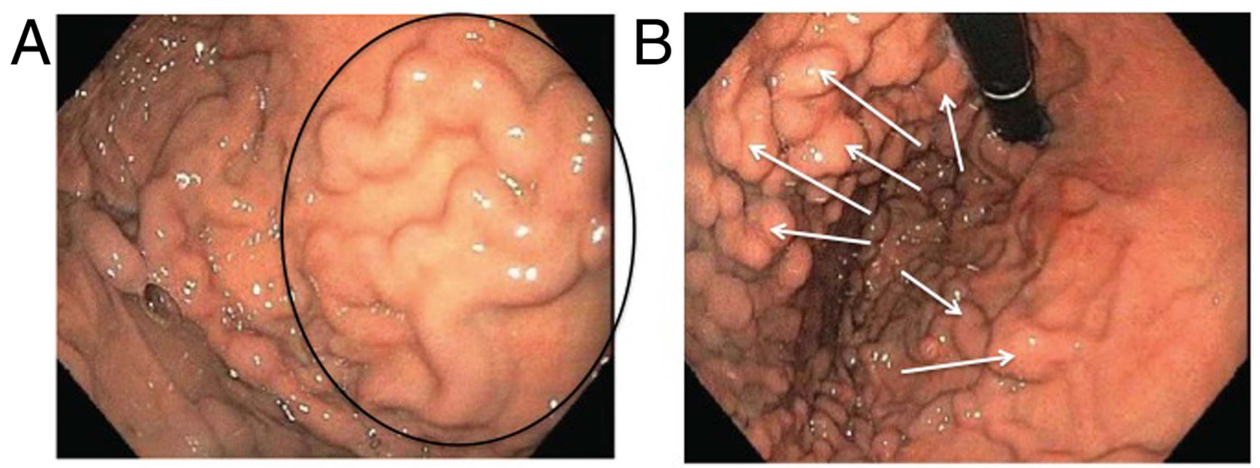

Figure 1 Upper gastrointestinal endoscopy report. Gastric varices in the fundus are shown in panels (A) (circled) and (B) (arrows).

\section{TREATMENT}

Patient consent was obtained to perform an abdominal exploration with possible splenectomy and, due to her abnormal liver function tests, liver biopsy. After opening the abdomen, approximately an hour was spent lysing extensive adhesions secondary to the previous pancreaticojejunostomy. After extensive adhesiolysis to enter the lesser sac, dissection continued up the greater curvature of the stomach with transection and ligation of large gastric varices involving short gastric vessels. Pathological examination showed an unremarkable spleen and liver samples. The postoperative diagnosis was gastric varices secondary to splenic vein occlusion, adhesions, and GI bleeding secondary to gastric varices.

\section{OUTCOME AND FOLLOW-UP}

Three months following splenectomy, the patient was back to full activity and no longer anaemic.

\section{DISCUSSION}

Gastric variceal bleeding due to SVT is an uncommon complication of pancreatitis that accords with the patient's history. Pancreatitis-induced SVT can occur because the splenic vein lies against the posterior surface of the pancreatic tail, and repeated

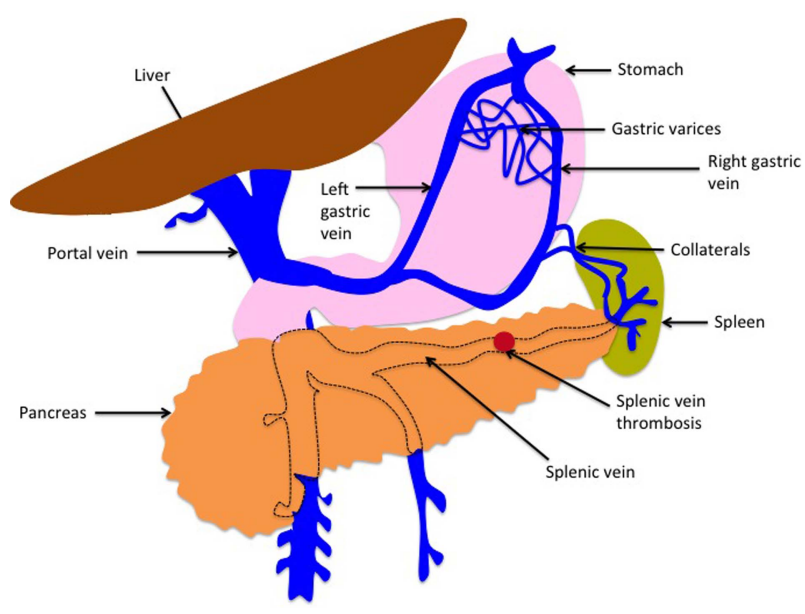

Figure 2 Development of splenic vein thrombosis. Splenic vein thrombosis may result from pancreatitis, which can compress the splenic vein or cause local, pro-thrombotic, inflammatory changes in the vascular endothelium. Blockage of the splenic vein leads to sinistral portal hypertension and the development of collateral vessels to circumvent the thrombus. Gastric varices form when pressure builds up within the submucosal veins of the fundus. pancreatic inflammation can damage the vein directly, compress it externally, and lead to thrombosis (figure 2). ${ }^{3} 4$ Occlusion of the splenic vein produces localised sinistral, or left-sided, portal hypertension, which is distinct from the common condition of generalised portal hypertension. Sinistral portal hypertension leads to the development of collateral vessels that circumvent the occluded splenic vein, most commonly by connecting to the short gastric vessels. Increased pressure within the submucosal veins in the gastric fundus results in varices. Oesophageal varices may sometimes form, but collaterals that connect to the oesophageal veins can usually drain through the left gastric (coronary) vein. The presence of isolated gastric varices without oesophageal varices strongly suggests SVT.

In this case, no source of overt bleeding was identified in the upper GI tract on endoscopy and push enteroscopy. A second reading of the abdominal and pelvic CT was necessary to detect dilated perigastric and perisplenic veins. Repeat endoscopy then confirmed the existence of gastric varices, which can be difficult to identify when not suspected or volume depleted. Fundic varices are commonly overlooked on endoscopy because they may be obscured by rugal folds. ${ }^{8}$ On endoscopy, gastric varices may appear as a cauliflower-like mass at the summit of the fundus; a lobulated, clubbed cystic swelling along the lesser curve of the stomach below the cardia; tortuous and ruga-like shapes in the fundus; or a network of vessels in the fundus, body or antrum. ${ }^{9}$

A majority of patients with variceal bleeding from SVT have splenomegaly, but in this patient the spleen and other abdominal organs appeared normal. The varices are the likely aetiology of the melena since normal results were obtained with colonoscopy, push enteroscopy and capsule endoscopy. The patient's history of childhood pancreatitis without cirrhotic liver disease might have prompted suspicions of gastric variceal bleeding from SVT, although that episode had occurred many years previously and was presumed to be trauma related. In addition, her

\section{Learning points}

- Gastric varices can be a commonly overlooked source of upper gastrointestinal bleeding.

- Gastric variceal bleeding due to splenic vein thrombosis is an infrequent complication of pancreatitis that can be difficult to identify on endoscopy.

- The presence of isolated gastric varices strongly suggests splenic vein thrombosis, and bleeding can be managed with splenectomy. 
bleeding must have been intermittent, which made it difficult to pinpoint its source during her initial hospitalisation. However, once the presence of isolated gastric varices was identified, a diagnosis of SVT was quickly deduced, without occlusion actually being visualised.

Acknowledgements Thanks to Jennifer Moon, PhD for her research and writing assistance on this manuscript.

Competing interests None.

Patient consent Obtained.

Provenance and peer review Not commissioned; externally peer reviewed.

\section{REFERENCES}

1 Liu K, Kaffes AJ. Review article: the diagnosis and investigation of obscure gastrointestinal bleeding. Aliment Pharmacol Ther 2011;34:416-23.
2 Hirschfeldt H. Die Erkankungen der Milz: Die Hepatolineal Erkankungen. Berlin: J Springer Verlag, 1920:384.

3 Sakorafas GH, Sarr MG, Farley DR, et al. The significance of sinistral portal hypertension complicating chronic pancreatitis. Am J Surg 2000;179:129-33.

4 Weber SM, Rikkers LF. Splenic vein thrombosis and gastrointestinal bleeding in chronic pancreatitis. World J Surg 2003;27:1271-4.

5 Butler JR, Eckert GJ, Zyromski NJ, et al. Natural history of pancreatitis-induced splenic vein thrombosis: a systematic review and meta-analysis of its incidence and rate of gastrointestinal bleeding. HBP (Oxford) 2011;13:839-45.

6 Heider TR, Azeem S, Galanko JA, et al. The natural history of pancreatitis-inducted splenic vein thrombosis. Ann Surg 2004;239:876-82.

7 Agarwal AK, Kumar R, Agarwal S, et al. Significance of splenic vein thrombosis in chronic pancreatitis. Am J Surg 2008;196:149-54.

8 Thakeb F, Salem SAM, Abdullah M, et al. Endoscopic diagnosis of gastric varices. Endoscopy 1994;26:287-91.

9 Belli AM, Jennings CM, Nakielny RA. Splenic and portal venous thrombosis: a vascular complication of pancreatic disease demonstrated on computed tomography. Clin Radiol 1990;41:13-16.

Copyright 2014 BMJ Publishing Group. All rights reserved. For permission to reuse any of this content visit http://group.bmj.com/group/rights-licensing/permissions.

BMJ Case Report Fellows may re-use this article for personal use and teaching without any further permission.

Become a Fellow of BMJ Case Reports today and you can:

- Submit as many cases as you like

- Enjoy fast sympathetic peer review and rapid publication of accepted articles

- Access all the published articles

- Re-use any of the published material for personal use and teaching without further permission

For information on Institutional Fellowships contact consortiasales@bmjgroup.com

Visit casereports.bmj.com for more articles like this and to become a Fellow 